Susan Bell's book Classification of Mammals (Columbia University Press, 1997). But the PhyloCode (www.ohio.edu/phylocode) - a set of rules governing phylogenetic nomenclature that in recent years has gained many proponents among zoologists and palaeontologists
- is not mentioned in the book. In the final chapter, Rose provides a summary of the idea of a sudden explosion of mammals after the Cretaceous-Tertiary boundary.

This beautiful and thorough book will be an essential tool for all those who work on fossil and extant mammals, and for both advanced undergraduate and graduate students. It is a 'must buy' for palaeontological libraries. Zofia Kielan-Jaworowska is at the Institute of Paleobiology, Polish Academy of Sciences, Warsaw, Poland.

\title{
Mysteries of female anatomy
}

\section{Secrets of Women: Gender, Generation, and the Origins of Human Dissection by Katharine Park \\ Zone Books: 2006.300 pp. \$36.95}

\section{Rina Knoeff}

Although the history of dissection in general has received increasing attention, the importance of anatomizing female bodies has hitherto been neglected. Katharine Park's Secrets of Women is a first attempt to fill the gap. She relates a fascinating history of women on the dissection table. Central to her book are the almost unbelievable stories of an abbess whose heart contained a cross, a crown of thorns, nails and a lance, items well known as symbols of the Passion of Christ; the investigation of the body of a lactating virgin prophetess; the search for the cause of death of patrician wives and mothers; and the dissected body of an executed female criminal. The accounts are bizarre yet captivating, as they portray the opening of the body not only as a medical procedure, but also as a cultural practice embedded in religious and social life. Park also exposes the myths that in the wake of Pope Boniface VIII's bull Detestande feritatis in 1299, the opening of bodies was surrounded by a cultural taboo, and also that anatomical practice was primarily a male practice studying male bodies.

Park argues that from the mid-thirteenth to the mid-sixteenth century, Italians understood their bodies both in terms of religion and in relation to family and kinship, and that this particular way of viewing the body shaped dissection practices. Male uncertainty regarding fatherhood (were they really the fathers of their children?), the existence of female-only knowledge regarding sexuality and generation (mainly related to inordinate sexual appetite, abortion practices, the exercise of sexual autonomy and the exertion of power over men), as well as the functioning of the reproductive system inside the female body, culminated in an excessive interest in what came to be known as 'the secrets of women'. As a result, Park argues, the uterus (and hence the inside of the female body) became a focal point of anatomical research in Italian patriarchal society.

Related to the opening of mothers' bodies, dissection practices concentrated on holy women. Not only did women manifest religious experiences in a particular corporeal way, but these experiences were also described in physiological terms of pregnancy. It was, for

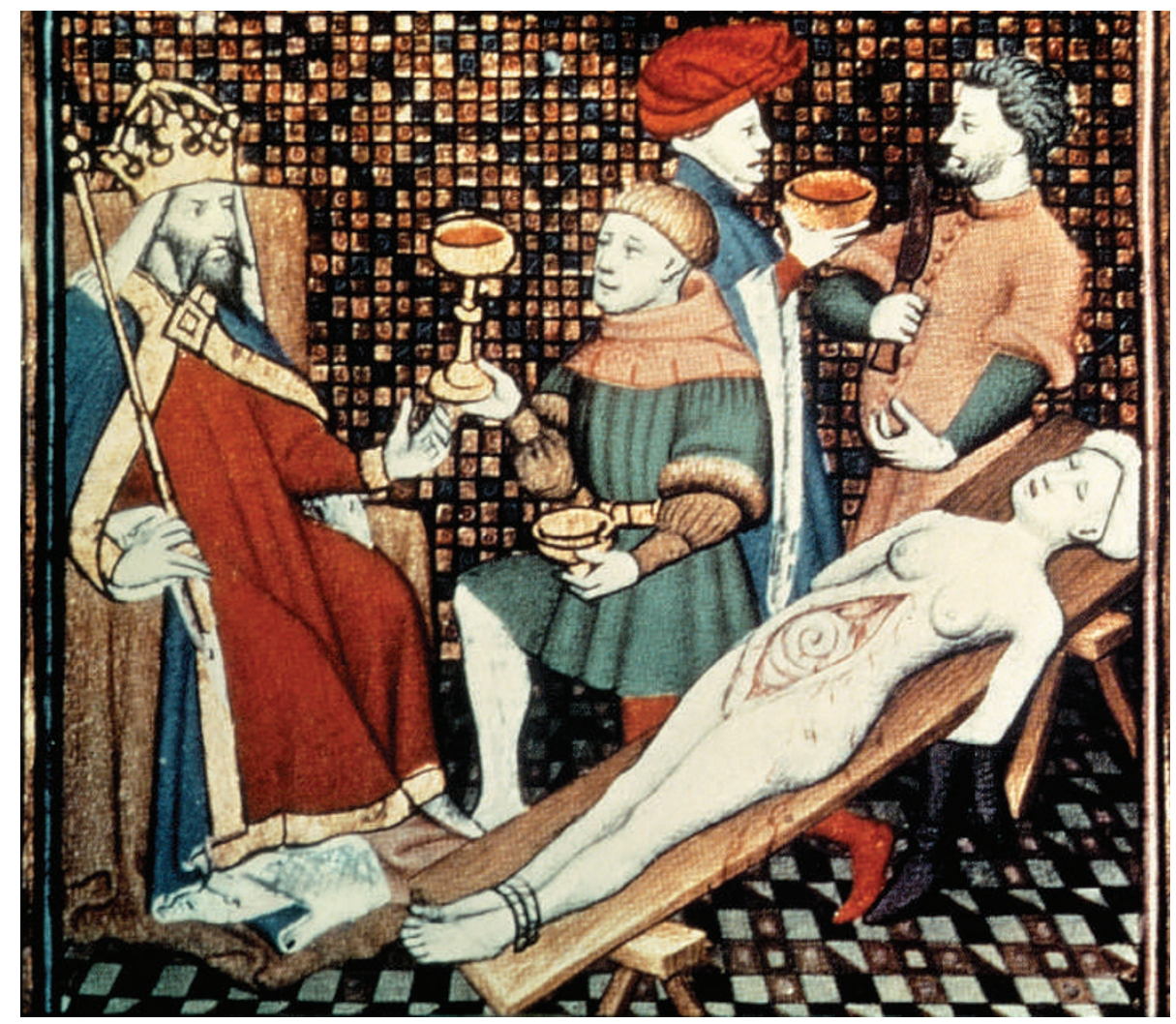

The dissection of female bodies had religious and familial significance in the fifteenth century.

instance, believed that Christ's presence in the heart would create new life in the same way as the father's seed in the mother's uterus. According to Park, the themes of holiness, generation and female corporeality together contributed importantly to the history of dissection.

At times, however, Park's interpretation is merely suggestive and the historical proof wafer-thin. For instance, her argument that holy women generate relics much as mothers generate children is well argued. But her suggestion that the dissection of holy women in order to extract relics can be viewed as a religious variant of a caesarean section, in which a baby was removed from a dead mother's body so it could be baptized, seems far-fetched.

In a similar vein, Park's understanding of religion is sometimes rather naive. Her interpretation of Christianity as exclusively Roman Catholic is understandable given the Italian context she describes, but it leaves no room for a pluralist view of religion. For Park, depictions that lack characteristically Roman Catholic symbols don't seem to count. For example, she interprets the frontispiece of Andreas Vesalius' book on human anatomy De humani corporis fabrica as secular, simply because there are no Catholic icons. Yet, particularly given Vesalius' Protestant upbringing, it can, and perhaps should, be viewed as a Protestant depiction (as other historians of medicine have done before).

Nevertheless, Park's book will undoubtedly prove to be an important contribution to the history of anatomy. For the first time it extensively discusses the history of anatomy from the viewpoint of the corpse and, because of its particular focus on women's bodies, it will radically change the way we think about the (male) history of the anatomized body. As such, the book is a 'must read' for anyone working on the history of pre-modern medicine. But because of its lucid style and fascinating argument, it is also surprisingly accessible, and I recommend it to anyone interested in the history of anatomy.

Rina Knoeff is in the Faculty of Arts, University of Leiden, 2300 RA Leiden, the Netherlands. 